\title{
Autism, Expert Discourses, and Subjectification: A Critical Examination of Applied Behavioural Therapies
}

\author{
JULIA F. GRUSON-WOOD \\ York University, Canada
}

ABSTRACT Applied behavioural therapies are widely adopted interventions that have become the standard of healthcare and expert knowledge for autistic people in Canada. These therapies are methods of individualized behavioural modification whereby skills are taught, and socially "undesirable" or "inappropriate" behaviour is regulated according to expert claims that focus on correction, imitation, repetition, reinforcements, and environmental modification. Despite their prevalence, these therapies are highly controversial methods within autism communities, with mostly non-autistic parents and clinicians as their main proponents, and autistic self-activists as their critics. The ethnographic research presented will examine the culture, training, and knowledge practices of behavioural therapy providers in Ontario, to study disciplinary techniques that are used to create expert subjects. In order to operate as a technology for producing optimal results in the autistic subject, working as a behavioural therapist involves multiple techniques such as completing intensive exercises consisting of audible and textual surveillance, recorded sessions, and intratherapeutic replicability. These techniques and exercises often work to discipline expressions of care in accordance with a "psychocentric" framework for understanding autism and supporting autistic people.

KEYWORDS applied behavioural therapies; critical autism studies; ethnography;

Foucault; psychocentrism; healthcare

Applied Behavioural Analysis (ABA) and Early Intensive Behavioural Intervention (EIBI) have become widely adopted therapies in the healthcare for young (18 months to seven years of age) autistic people (Orsini, 2009). ${ }^{1}$ This age range is considered the optimal window for EIBI (Gordon, 2012;

\footnotetext{
${ }^{1}$ I refer to those with autism as "autistic people" as this is the term favoured by many autistic activists who consider autism a political identity.

2 "Neurodiversity" is a term used by many in autistic communities, and refers to the existence of Correspondence Address: Julia F. Gruson-Wood, Department of Science \& Technology Studies, York University, 4700 Keele St., Toronto, ON, M3J 1P3; Email: juliagrusonwood@gmail.com
} 
Perry, 2002), although ABA methods may be applied throughout the lifespan of autistic people in North America. Based predominately on B. F. Skinner's (1938) theory of operant conditioning, ABA and EIBI are referred to by expert proponents as evidence-based methods. ABA and EIBI are individualized behavioural modification techniques that focus on improving cognitive, communication, and life skills. Correcting behaviour deemed inappropriate or socially undesirable is a large component of many applied behavioural therapy programs (Lovaas, 1987; Ontario Ministry of Education, 2007). Individualized behavioural programs use techniques such as imitation, repetition, reinforcements, and environmental modification to improve communication and cognitive skills (Lovaas, 1987; Ontario Ministry of Children and Youth Services, 2016).

Behaviour modification techniques are an important area of study as they exemplify psychocentrism (Rimke, 2010a, 2010b), the view that all human problems are individually rooted rather than socially constituted. The normative liberal democratic ideal of the self-governing modern subject has been imposed and enforced on autistic people (Eyal et al., 2010), and especially on autistic children who by virtue of their age are incapable of providing informed consent. Intelligence, autonomy, and functioning are dominant values that undergird behavioural analysis. ABA and EIBI are thus often forms of social and moral evaluation based on socially derived value judgments rather than objective or neutral science (Turner \& Edgley, 2005). As examined primarily in the scholarship of Michael Orsini (2009, 2012; Orsini \& Smith, 2010) there are two major clashing health social movements relating to autism: the dominant autism movement (primarily non-autistic clinicians and parents), which views autism as a deficit to be fixed, cured or prevented through clinical, genetic, or biomedical intervention; and the marginalized autistic movement (primarily autistic people and allies), which views autism as a form of difference and autistic acceptance as a civil rights issue. This paper provides a critical analysis of the dominant "psy" framework imposed on autistic people by the autism movement.

The analysis that follows examines the disciplinary procedures and exercises required to work as a behavioural therapist or parent parapractitioner. This research is strongly influenced by the scholarly contributions of Michael Orsini (2009, 2012), who examines autism advocacy as its own social movement, and Michelle Dawson (2004, 2005, 2008), who analyses the ethics, science, politics and history of ABA and EIBI. Theoretically, the paper draws on Michel Foucault's work on discipline (1995), Byron Good's (1994) ethnographic examination of the training of medical students, and Heidi Rimke's (2010a, 2010b) critical sociological theory of psychocentrism.

The growing voices of resistance to - and proliferation of - behaviour modification therapies, highlights the importance of critical scholarly attention to these therapies. Situated within the fields of science studies, medical anthropology, and critical autism studies (see Davidson \& Orsini, 
2013), this research study seeks to analyze the ABA/EIBI-dominated culture of autism services in Ontario. Following Foucauldian scholarship, this study also analyzes the power and knowledge practices of experts and providers working within autism services. It is important to study service providers, because until now they have not been the focus of critical social scientific studies within the field of autism. This is a significant gap, as science studies scholars have demonstrated how scientific methods, disciplines, and those working within them, are situated in specific "epistemic cultures": "machineries of knowing" comprised of specific social, political, and economic contexts that shape expert knowledge and evidence production (Knorr-Cetina, 1999, p. 364). Institutional resources, employee relationships, and bureaucratic processes are also fundamental to the creation of scientific theories (Traweek, 1992). Hence, scientific knowledge is not absolute or value-neutral, because scientific work operates in the context of culture and power. The epistemic culture of a scientific field can begin to be revealed through empirical analyses of the everyday work conducted therein (Latour, 1988).

This study relies on an ethnographic methodology for the intimate and extended opportunity it provides for multi-sited empirical observation (Marcus, 1995). Theoretically informed analysis of detailed empirical data is central to ethnography (Clifford, 1986), as is researching from a positionality within the culture being examined (Abu-Lughod, 1991; Fabian, 1990). My fieldwork, conducted over the course of 15 months, included observation research at autism conferences, exhibits, and events, and interviews with 29 providers and recipients of applied behavioural therapies. Working as an educator for an autistic youth, and being the sibling of an autistic person, contributed to my knowledge of and experience with the practices, policies and infrastructure of Ontario autism healthcare delivery. With the exception of one informant who chose not to be recorded, all confidential interviews have been transcribed in full, and all participants are referred to using a pseudonym.

\section{Contested Knowledge Claims}

As the only funded services that are guaranteed for autistic children and youth in Ontario, applied behavioural therapies govern autism healthcare delivery provincially (and nationwide). It is also mandatory for public school teachers to provide ABA to their autistic students (see Ontario Ministry of Education, 2007). Further, most ABA/EIBI centers offer funded parent training programs (Ontario Ministry of Children and Youth Services, 2016; Perry, 2002), so that family members can be drawn in as unpaid parapractitioners who maintain this approach at home (Donzelot, 1997; Eyal et al., 2010; Silverman, 2012; Solish \& Perry, 2008). Behavioural therapy services are also used to improve life skills and correct behavioural 
"problems" of autistic adults residing in in-patient units or group homes, or who attend day programs (see Behaviourprise Consulting Inc., 2015). Hence, $\mathrm{ABA}$ and EIBI are ubiquitous in many autistic people's everyday lives.

Despite the prevalence of ABA and EIBI, they are highly controversial methods within autism communities (Bagatell, 2010; Vermey, 2004). Although parents and clinicians are often strong proponents, having even launched human rights cases for ABA and EIBI to be classified as medical necessities (Autism Society of Canada, 2012; Auton vs. British Columbia, 2002-2003; C.R. vs. Alberta, 1996; Hammer, 2008; F.E.A.T, 1996-2014), autistic self-advocates (some having received ABA and EIBI) are often very critical of these methods. This is evident from the legal and social media testimony provided by autistic people who have criticized these interventions as non-consensual and scientifically unethical (Bagatell, 2010; Dawson, 2005; Solomon, 2008). Critics have also denounced ABA and EIBI as oppressive, normalizing, corrective methods with the intention to eradicate autism (AnxiousAdvocate, 2015; Dawson, 2004; Schaber, 2014; Sequenzia, 2016; Unstrange Mind, 2014).

Meanwhile, the dominant discourse of many of the parent and clinician-run autism organizations has excluded anti-ABA autistic critics, arguing that their ability to speak for themselves means they are not autistic enough to speak for so-called lower functioning autistic children (Bagatell, 2010; Baggs, 2007; Jager, 2010; Orsini \& Smith, 2010; Orsini, 2012). Defining autism as a deficit to be fixed masks the social effects of categorization that takes the non-autistic person as the standard of normality. The disputes about ABA and EIBI have been intense, with the stakes being both the welfare of autistic people and the legitimacy of behavioural modification therapies as the dominant expert research enterprise for supporting autistic people and their families.

\section{Psychocentrism}

Nikolas Rose (1998) argues that the modern liberal subject knows itself through various truth techniques invented by the psy disciplines, and defines itself as autonomous yet obligated to make ethical self-reflective choices. It is through the psy disciplines that behaviour became calculable, measurable, and open to intervention, and that normality became an enforced ideal. This proliferation of, and subjection to, psy truths and subjectivity, has resulted in what Heidi Rimke has termed, "psychocentrism": "the cultural domination by, and consumption of, psy discourse that simultaneously depoliticize the political while capitalizing on the emotional through the hegemony of political practices of power" (2010a, p. 95). Psychocentrism, as a form of ableism, characterizes "all human problems" as "innate pathologies of the individual mind/body" (Rimke, 2010a, p. 96). Some of these so-called pathologies, like autism, are considered evil and tragic epidemics constituting 
states of emergency that require expert treatment and prevention (Broderick \& Ne'eman, 2008; Thierry, 2006; Wright, 2013). Perceptions and classifications of normality and pathology are shaped by neoliberalism (Rimke, 2010a, 2010b). As articulated by Catherine Runswick-Cole (2014, p. 1126), "autism has been subjected to, produced by and exchanged within neoliberal market systems." A psychocentric view hyper-responsibilizes the so-called pathological individual (or with autism, primarily the parents) to seek clinical/psy guidance to "get well," above all else (Rimke, 2010a). In psychocentric discourse the forces of power and socially structured injustices are erased by reductively placing all responsibility on the individual (Rimke, 2010a, 2010b).

As many autistic self-activists have been asserting (Autistic Self Advocacy Network, 2015; Baggs, 2007; Ne'eman, 2011; Sequenzia, 2014; Sinclair, 2002), and as perpetuated by most mainstream autism organizations (see Defeat Autism Now, 2007; Autism Speaks/Cure Autism Now, 2006; Robinson, 2013), psychocentric attitudes toward neurodiversity govern the dominant cultural response to autistic people and their healthcare. ${ }^{2}$ Mainstream autism culture capitalizes on "emotional practices of power" (Rimke, 2010a, p. 95) - especially pity, fear, sadness, blame, anger, hope, inspiration, and despair - to increase the symbolic, political and economic capital of clinical, charity and recovery based approaches to autism care. The depoliticization of autism as a tragic health epidemic over-responsibilizes parents and clinicians to "light it up blue" for donations for research: to spread autism acceptance while simultaneously "walking for the cure." Autism thus presents a strong example of the hegemony of the "disease model of autism" (Broderick \& Ne'eman, 2008, p. 459) that negatively affects the lives of autistic people.

\section{Behavioural Technologies and Constituting Subjects}

Building upon B. F. Skinner's technology of behaviour (1938, 1971), Ole Ivar Lovaas, a clinical psychologist based at UCLA, was the pioneer for autism-specific ABA in the 1960s, and later for EIBI (Lovaas, 1987; Rutherford, 2009; Silverman, 2012). EIBI is an intensive ABA program, consisting of about 40 weekly hours of one-on-one ABA work. Individual intervention plans are devised that use positive and negative reinforcements and sometimes aversives - to target skills and behaviours requiring improvement and replacement (Lovaas, 1987; Ontario Ministry of Children

\footnotetext{
2 "Neurodiversity" is a term used by many in autistic communities, and refers to the existence of neurological variegation in a social system that privileges or oppresses people based on their relation to neurological norms. For an important critique of neurodiversity as reinforcing neoliberal identity politics, see Runswick-Cole (2014).
} 
and Youth Services, 2016). ${ }^{3}$ Targeted behaviour could include learning to speak and communicate needs, use the toilet, count, build social skills, make eye contact, stop tantrums, or reduce stimming (self-stimulation). Interventions may take the form of quick, short proscriptive sessions that are repeated until mastered - this is one of the most popular methods, called Discrete Trial Training (Smith, 2001). Other common therapeutic interventions include natural environment or incidental training, and pivotal response therapy.

Lovaas described autism as a collection of dysfunctional behaviours that may be cured through intense behavioural work (Dawson, 2004; The Lovaas Center, 2016; Lovaas, 1987). According to Lovaas, when he began applying $\mathrm{ABA}$ and EIBI, the primary goal of behavioural therapy was to free people enslaved by autism (The Lovaas Center, 2016). To be free from autism, Lovaas asserted that the autistic person must engage with behavioural therapy work "during every waking hour" (Zucker \& Donovan, 2016, p. 216), thus effectively clinicalizing their everyday life. To pervasively engage in behavioural therapies, Lovaas responsibilized parents to conduct ABA in the home. Thus, family and parental styles were reshaped to conform to the goals and exercises of the clinic (Zucker \& Donovan, 2016). Lovaas' approach was clearly psychocentric given that the therapeutic focus of behavioural therapy was premised on individual - not social - change. This formulation of individualized social control reinforced existing social structures of essentialist neurological inequality, putting the onus on the autistic person to conform to constructions of neurotypicality. ${ }^{4}$

The science of behavioural therapy is based on the notion that all behaviours have a function that is measurable and changeable through scheduled reinforcements and environmental control (Lovaas, 1987; Rutherford, 2009; Skinner, 1938, 1971). In behavioural analysis, there is no mind or psyche, only thoughts, behaviour, and environment. Behavioural analysis brings the self to the surface (see Novas \& Rose, 2000), as an object that is exterior and visible, and therefore more available for acting upon. Hence, "Skinner's most enduring achievement was to treat human behaviour change like any other technological problem" (Rutherford, 2009, p. 10). This technology of behaviour is applied to make the technology of the self function better.

\footnotetext{
${ }^{3} \mathrm{~A}$ basic definition of an aversive is a punishing or unpleasant stimulus (i.e., slapping, hitting, taste aversives, electric shocks) applied primarily to stop a harmful or negative behaviour. Aversives are widely considered unethical and out-dated, although five of my informants - as well as colleagues in the autism field - witnessed providers who apply them. One informant discussed using them.

${ }^{4}$ Importantly, not all behavioural therapists and behavioural science methods are psychocentric. While space prohibits more analysis, some behavioural therapy providers work against a psychocentric framework of supporting autistic people (see Shyman, 2014).
} 


\section{Disciplinary Power}

As a population subjected to intensive governing modes of expert power and knowledge, autistic people are subjected to a "micro-physics" and "machinery" of power (Foucault, 1995, p. 139, 26) when receiving ABA or EIBI. By viewing behaviour as a technology to be tracked, replicated, calculated and modified through highly controlled environmental manipulations (Rutherford, 2009, p. 7, 10), behavioural analysis treats the autistic body like a machine as it "breaks it down and rearranges it" to operate more effectively (Foucault, 1995, pp. 138-139). Of course, all people are subjected to disciplinary power (Foucault, 1991; Foucault, 2008). What autistic self-advocates and allies have exposed is that autistic people - in often being categorized as abnormal - are likely to be subjected to hyperintensive disciplinary procedures. What requires further analysis is how the subjectivity of the behavioural therapist must be disassembled and reconstructed; it is "calculated, organized, technically thought out" (Foucault, 1995, p. 26), so that it can operate as a technology for producing "effective" results in autistic subjects. Behavioural therapists are subjected to disciplinary techniques that mirror the ones they apply to their autistic subjects. Thus, the behavioural therapist is trained and disciplined to function as a "productive" "subjected," "practised," "effective" and "obedient" docile body (Foucault, 1995, p. 138).

The testimony of a behavioural therapist informant called Natalie illustrates this. Natalie explained how she was trained in the intensive "gold standard" model of "errorless teaching," involving instruction, modeling, rehearsal, and feedback exercises. In training, Natalie was shadowed and shaped by senior therapists, had monthly "maintenance checks" testing her performance abilities, and had to pass "mastery criteria" assessments. Natalie described using the same techniques to shape the conduct of her autistic subjects, thus demonstrating the relationship between the governance of the self and others. Natalie succinctly articulated the co-production (see Jasanoff, 2006) of the disciplining of the therapist with the autistic subject: "when it's intensive it's not just intensive for the kids, it's intensive for the staff. You would do 300 something... teaching trials, and that's in addition to behavioural intervention."

Through disciplinary practices and technologies of surveillance such as recorded assessments, cross-therapist replicability and textual compliance, many behavioural therapists learn to "inhabit a new world" (Good, 1994, p. 70), a behavioural world. In this behavioural world, behavioural therapists learn to relate to themselves as malleable instruments, who through objective, authoritative and compliant conduct, are able to engineer targeted therapeutic outcomes. It is common in the applied behavioural therapy field to consider autism as a collection of individual deficits that require improvement. Thus, to ethically care for an autistic person means working to increase their functionality. As a result, both the "good" autistic person and the "good" 
behavioural therapist emerge through training exercises of discipline and compliance.

\section{Juggling Robots and Identities: The Making of a Behavioural Therapist}

Margot, a former ABA therapist in her mid-30s, recounted her experience of being trained as an instructor therapist at a public EIBI centre while in her mid-20s, describing her cohort as young and energetic, all of them eager to get their autistic subjects to respond to therapy work. She stated:

My friends... they could hear each other over their partitions with their kids and we would talk about how crazy we would get to try and get the kids... socially reinforced... And one of them heard the other one being like 'I'm a juggling robot!' [loudly and clownish] and then the child would laugh and then perform... Like 'match the cards!' Or whatever. The kid would do it. But we were all like: 'What are we doing? Like with ourselves?'

In describing attempts to get their "kids" to perform, Margot painted a frenetic picture of a therapist's desire to incite specific responses. Margot's story also vividly captures the intensive bodywork involved in being a behavioural therapist. When speaking to me, Margot had a low voice and calm demeanour, but when imitating her friends' tone in speaking to her kid, she raised her voice an octave to a cartoonish, almost shrill tone, startling me so that my body moved back. The tone and wild actions involved in becoming a juggling robot indicate the extent to which behavioural therapists modify themselves to work as instruments for accomplishing targeted responses in their "individuals." ${ }^{5}$ This process of identity rupturing and formation was succinctly captured in the stunned reflection Margot and her friends shared: "What are we doing? Like with ourselves?"

Medical anthropologist Byron Good (1994) examined the disciplinary practices involved in becoming a physician, and detailed how these practices reshaped the emotional life and worldview of medical students. Like Erving Goffman's (1961) work on the "total institution," Good (1994) argues that training to be a doctor is a total process - like training for the army - that requires an unmaking and reconstructing of the medical students' worldview. As Good (1994, p. 72) observes, "within the lifeworld of medicine, the body is newly constituted as a medical body, quite distinct from the bodies we interact with in everyday life." Good (1994, p. 72) continues to explain how an "organized set of perceptions and emotional responses" arise with the "emergence of the body as a site of medical knowledge." As with medical training, becoming a behavioural therapist often involves breaking down and rebuilding the therapists' way of perceiving the world, themselves and others.

${ }^{5}$ I use the term "individual" to refer to the autistic people the behavioural therapists work with, as this is the language the behavioural therapists being interviewed most commonly used. 
In the process, the therapist's body becomes an object of subjectification and a subject of objectification.

As exemplified by the evocative figure of the juggling robot, there are complex gendered dynamics at play with female behavioural therapists' selfgovernance and training. This is especially significant because behavioural therapy is a feminized profession. Juggling is commonly associated with the double-day of contemporary heteronormative motherhood involving both public and private labour. A robot is a hyper-masculinized technological and mechanical object, devoid of emotion and personality, and created to serve functional purposes. Skinner's technology of behaviour (a fundamental principle of Lovaas' ABA/EIBI), could be interpreted as figuratively robotic. Many of the female behavioural therapists interviewed juggled masculine ideals of objective scientific rationality (in becoming a technical instrument for producing behavioural change), and socialized ideals of feminization (nurturing, empathy, kindness). Chloe Silverman (2012) claims that parents and clinicians use love as a technical tool to push for resources and funding for clinical treatments and interventions for autism. My study demonstrates that behavioural therapists also cite feelings of affection as an important reason why they choose to conduct behavioural therapy work. That applied behavioural therapy is a feminized field elucidates how the affective topography of ABA and EIBI is situated within a "gendered economy of care" (Silverman, 2012, p. 6).

\section{The Panopticon: Audible and Textual Surveillance}

Margot described the clinic as divided by partitions, where one-on-one work was audible - but not visible - to other behavioural therapy providers and recipients. As anyone in the room could hear a therapy session, including supervisors who write behavioural plans, the partitions prevented participants from knowing who, or whether, anyone was listening. This arrangement recalls Foucault's architectural metaphor of the panopticon, which he used to describe social relations of surveillance and regulation (Foucault, 1995). The panopticon was designed so that a single overseer could watch all the inmates of an institution, but where inmates could not see each other or the overseer, thus knowing there was always the possibility of being surveilled (Foucault, 1995). Foucault writes:

He who is subjected to a field of visibility, and who knows it, assumes responsibility for the constraints of power; he makes them play spontaneously upon himself; he inscribes in himself the power relation in which he simultaneously plays both roles; he becomes the principle of his own subjection. (Foucault, 1995, pp. 202-203)

Margot, her colleagues, and the kids, were subjected to a similar form of regulatory power. Surveillance created a collectivizing bond amongst 
therapist-colleagues about the "crazy" extent of their attempts to discipline their own conduct to produce responses in their autistic subjects. Added to this is the strong desire of the therapists to succeed in modifying their kid's performance, which is rooted in a desire to be judged a good behavioural therapist. The criterion to be a good therapist is the ability to elicit the correct responses in an individual by conducting their conduct through the selfgovernance of the self and others (Foucault, 1991; Foucault, 2008). With the juggling robot technique, the intended correct response was social engagement (hence, laughter), which the therapist achieved by transforming herself into a comical subject. Thus, the sound of her kid's laughter communicated to the other therapists - and perhaps to the clinical supervisor who might be listening - that she was doing a good job.

Texts, in the form of behavioural plans or stemming from data collection exercises, are another instrument of panoptic surveillance. As many of the behavioural therapists interviewed indicated, in order to understand the function of a behaviour and intervene for betterment, data collection exercises are often completed before, during, and after each behavioural therapy session. The purposes of data collection include empirical observation, behavioural tracking, behavioural therapy research production and surveillance. The governing text for one-on-one ABA and EIBI work is the behaviour plan. This document disciplines the micro-conduct of a therapist's body and actions when applying behavioural therapy. It is a detailed document that includes all the interventions to be carried out by the therapist. It is created by the clinical supervisor after an individual has completed an array of assessment procedures that reveal the skills and behaviours requiring replacement, modification, and improvement.

The importance of the behaviour plan in governing all actors involved in applying behavioural therapies cannot be underestimated. Leon (a former assistant behavioural therapist at a public EIBI clinic who is now a $\mathrm{PhD}$ student) referred to the plan as "the Bible" for behavioural therapists as it is treated like "the word of God" and "dictates everything you do." As Leon explained, there are negative consequences for not following the word of God, including routine check-ups conducted by clinical supervisors who regularly monitor the data collection documents completed by the therapist. Supervisors reprimand or praise the therapist for compliantly completing the procedures outlined in the behaviour plan. While the supervisor is not always watching a behavioural therapist's work, the use of texts ensures that therapists operate as if there is always the possibility of being watched. In turn, they learn to conduct themselves in compliance with the managerial authority of their behaviour plan, which enables supervisors to govern when absent.

A story told to me by Becky - a therapist working in a private EIBI clinic of what happened when she accidentally failed to follow one of the procedures written in her individual's plan illustrates how behavioural therapists internalize the expert authority of the clinical supervisor (via this 
document), and how they invoke and impose such textual authority on other therapists. Becky's description of her noncompliance is expressed in the following quote:

It's all written in their program. It's very specific... There were times I remember still to this day, one of the boys I was supporting... was actually not on task, and I didn't read it [the plan]. Silly me, I didn't respond properly...the other instructor, she came up and she said 'He's stimming!' and the stimming looked very normal. His hands were in his pocket... But I didn't know... [they] were fiddling with the string that was stitched into the seam... and that was written in his book but I didn't know... I just came in and I "shewwww!" - I looked over the book very fast... But I should have known... And then there was a correctionary procedure that has to be done.

By voicing regret and anxiety about missing a very subtle bodily cue that was written into the individual's plan, Becky demonstrated the important surveillance function of the document. Becky's description of her own sense of $\mathrm{ABA}$ as an empowering technique for autistic people, coupled with her eagerness to contribute to this study, compelled her to undertake ABA as a "vocation": an ethical calling, rather than a practical or economic one. Becky stated that for her, the job of behavioural therapist "has nothing to do with money," and that the pay was modest. Thus, Becky's hyperbolized feelings of humiliation about missing a stimm by skimming through "the book," are revealing of the training she has received to align being a good therapist with compliance to the behaviour plan. Further, as a document available for any behavioural therapist to read, the behaviour plan regulates the therapist to conduct herself as if always being monitored.

\section{Video Technologies: Recording Subjection}

The routine and panoptic video recordings of ABA sessions were discussed by many behavioural therapist informants, and by parent para-practitioners who had been trained to apply behavioural therapies to their child. Often informants would mention the recordings in passing, thus indicating the significance of this method of surveillance as a naturalized part of ABA work. Some clinicians I interviewed described recorded sessions as a key technology for assessing the performance and skills of both practitioner and recipient. Alternately, parents would watch their child's recorded therapy sessions as part of their parent-training program, for the purpose of learning to model the techniques used by the behavioural therapist. Parents would also watch videos of their own behavioural therapy work with their children to receive clinician feedback on their conduct and skills.

While many therapists and parent para-practitioners in this study were grateful for opportunities to receive supervision and feedback, some felt stressed when a recorded session was not going well. One therapist, Laurie, 
lost a job due to a negative parent assessment of her recorded session with their child. Laurie, herself autistic, was providing ABA in the home of the individual she was working with. The individual's parents were insistent that their child learn to make eye contact, and they wanted Laurie to use hands-on strategies to enforce this lesson. Laurie felt uncomfortable with this and resisted implementing these strategies. After reviewing the video of Laurie's work, the parents decided to terminate her employment. Laurie's story elucidates how the video recording is a form of surveillance that tacitly compels compliance. Further, it demonstrates both the stakes of the recording and its different uses by the multiple actors involved in providing or paying for ABA. Many behavioural therapists work in home-based programs, or for private clinics that are paid for by parents, meaning that they are sometimes governed both by parents and clinical supervisors. The therapists who work privately described how tricky it can be to manage the expectations of both types of employers. These therapists discussed the difficulties of negotiating their conduct so that it pleases both stakeholders (especially if their priorities clash), while also meeting their own ethical code. The pressure to shape conduct to satisfy conflicting expectations is heightened by the financial uncertainty of many non-unionized private behavioural therapy jobs. Laurie failed to perform this delicate dance, and after being fired, decided to leave the field.

Another function of the video recording is as a testing mechanism for behavioural therapy qualification. The grading scheme relating to recorded performances works to co-produce the success of the autistic subject with that of the therapist. For example, Tajman, a clinical supervisor who described her own training process, stated that she had to receive a passing mark on her performance - an $80 \%$ "mastery" score - in multiple recorded sessions to become a behavioural therapist. Tajman explained that therapists need their autistic individual also to master the session in order to be assessed as mastering the session themselves. This disciplinary technique teaches student behavioural therapists that they need their autistic individuals to provide the correct responses in order to be a good therapist. This enmeshment can compel an almost desperate desire for the autistic individual to master the correct performance, as evidenced with the story of the juggling robot.

\section{Performance and Replicability}

In addition to video surveillance, behavioural therapists' conduct is shaped through exercises of cross-therapist replicability. As mentioned, an autistic individual is often required to respond correctly to $80 \%$ of the session instructions in order to master it and move on. Many therapist informants explained that the mastered session has to be repeated three times with the same results, but by different therapists. To engineer replicable results, many

informants described having to learn to operate as a technical instrument for 
generating objective behavioural change. To complicate things, many therapists discussed the importance of building rapport - friendliness and trust - with their individual. Yet rapport has to be carefully managed as to not slide into a "relationship." Hence, rapport is used to advance behavioural therapists' ability to generate replicable effective behavioural performances, while a relationship contaminates this ability. To examine this form of discipline, I asked Leon to expand on the role of objectivity and emotional connection in $\mathrm{ABA}$ and $\mathrm{EIBI}$ practice, and whether these topics were included in his behavioural therapy training. Leon responded:

There was no specific training around it but... this is how it was explained: 'if you develop a relationship with a child it will excuse your ability to make further progress because your purview of their abilities is skewed, therefore you shouldn't do it.' It was almost like... a scare tactic. 'So by doing this, you're hurting more kids in the long run.' So... it was brought up, reinforced again, by the senior therapist.

The issue of relationships was mentioned during training and reinforced by Leon's supervisor as both a technical and ethical problem: a bond that would impede a child's progress, skew the therapist's understanding of the child's abilities, and thus hurt the child in the future. Leon describes these interventions as scare tactics meant to discipline his conduct. This sense of being disciplined is evident in Leon's description of his senior therapist as "reinforcing" and thus regulating him to keep a professional social distance.

\section{Authority, Compliance, and Care}

Maya, a 19 year-old assistant therapist, began working with an autistic teenager who she met when she was a camp counsellor. To Maya, becoming a behavioural therapist was both a vocation and a job. As a psychology major, ABA/EIBI was her most practical career prospect, but she also considered applied behavioural therapy methods as vital for helping autistic people.

Maya described her struggle with providing ABA. When asked to explain the source of her discomfort, Maya described having to actively temper her compulsion to "be nice" to provide effective ABA. If nice gets in the way of progress, being nice can actually be unkind, Maya explained. Thus, in training to become a therapist, Maya re-signifies niceness as harmful to her individuals' progress (this is similar to the logic presented to Leon regarding forming a relationship). Throughout the interview, Maya laughed nervously, spoke quietly, and smiled often. She appeared shy and warm, and spoke of her affection for the individuals with whom she works. It was evident that acting in a way that did not feel nice was challenging for Maya. The following interview excerpt provides context for Maya's rationale, and 
elucidates how her process of becoming a behavioural therapist involved breaking down and reconstructing her identity.

M: I still have a lot more to learn because there will be situations where I feel like I'm not being effective. Someone else who's been working with her [the individual] will be doing the exact same thing as me but will be effective... It's just about how you portray yourself... It's a lot about implicit authority... the way you stand, the voice you use, the tone... It's funny because I was... a very... diplomatic type of person to begin with. When I started this I felt like: 'Am I becoming rude? Am I being authoritative?'

J: Do you remember the growing pains when you first started implementing [intensive behavioural therapy]?

M: Still sometimes making her do things that she doesn't want to do. I think it's actually still the same thing: following through. I tend to... adapt to her, which I guess people would do in general... The thing you have to remember about ABA is that you're trying to help them be functional, so if you adapt to when they're being dysfunctional... you're not really helping them, right? If they're going to keep... throwing a tantrum and you're trying to adapt to that, that won't be right.

An important part of this excerpt is Maya's sense that her ability to become a good therapist is premised on her ability to produce the same level of effectiveness as other behavioural therapists. This indicates that Maya has been disciplined to view the merit of her work in terms of its cross-therapist replicability. Maya also discusses having to change how she portrays herself. She "began" as a diplomatic person, but in applying ABA, she questions whether she has become a different kind of person - a rude and authoritative one. Maya embodied these two kinds of people while she was explaining this to me. When referring to her diplomatic self, Maya was bubbly and animated, her back slouched, body leaning toward mine, and her hands expressive. When describing her therapist self, she shifted her posture dramatically; her back was rigidly straight, face blank, tone commanding and terse, and arms tucked under the table. These two identities were very different. When Maya explained behavioural therapy work as requiring her to refrain from doing what "people generally do" (i.e., adapt to the autistic person) she articulated how the process of becoming a therapist is constitutive of a new lifeworld, which involves unfamiliar perceptions, knowledge-practices, and ways of interacting. Maya still struggles to "follow through" with the practices required in this new behavioural lifeworld, and actively works to obey and make sense of them.

Maya's motivation for following through is linked to her newly-adopted behavioural orientation toward kindness, as well as to her practical hope for employment after graduation. Assistant behavioural therapists make a modest salary and often have little job security; senior therapists, behavioural consultants, and clinical supervisors usually have greater job security and higher salaries. Leon described a "chain of command" in ABA and EIBI 
work, descending from clinicians to supervisors, to behavioural therapists, with instructor and assistant therapists at the bottom. When I asked him how he felt about this chain, Leon responded:

I never had... any issues with them [his senior therapists] taking authority... I did what I was told to do... But that was my goal eventually, to keep moving up. So kind of the classic Foucauldian idea of being a good citizen, does good work, does what they want them to do, will have more success than the one that resists, right?

Maya's incentive to conduct herself to be as "effective" as other therapists working with her individual resonates with Leon's analysis of compliance as related to moving up the chain, where being a good citizen corresponds with conforming to organizational rules and norms of professional conduct.

In the second part of my exchange with Maya quoted above, she works to settle an uncomfortable discord between how she likes to act versus how she is being trained, citing "effective" forms of conduct as central to reducing her clients "dysfunctionality." Maya thus draws on behavioural language to organize her perception of autism as an innate individual deficit requiring behavioural intervention. She further uses behavioural science terminology to legitimize her new authoritative role. In transitioning from nice to authoritative, Maya's perception of how to express empathy shifted in sync with her new ethical framework. Maya still wants to be good, but she now sees good through the lens of behavioural analysis. In rejecting niceness, Maya understands her new authoritative conduct as a form of kindness, in which kindness ("helping") has been psychocentrically reduced to behavioural effectiveness.

The relationship between kindness and effectiveness was also explored in my interview with Anita, who lives with her parents, husband, and three children, two of whom are diagnosed autistic. She works as an unpaid ABA para-practitioner to her autistic children. Anita explained her knowledge of $\mathrm{ABA}$ as informed by the government-funded parent training programs she was encouraged to take after her children were diagnosed. She described applying severe interventions to her autistic children. Most parents use strategies to compel children to express themselves in relation to social norms of capacity, so it is important to note the particular ways that Anita was trained to parent as an authoritative, compliant behavioural therapist. It was clear that she loved her autistic children and thought ABA was the best thing she could do to help them. To understand the logic behind this understanding, I asked Anita about her knowledge of autism and ABA. I also invited her to describe how her kids reacted to ABA, and how those reactions made her feel. This is an excerpt from her response:

Lots of tantrums... That was challenging, being a mother. The challenging part is to withhold your emotions and... keep that child crying until he realizes that, 'okay she's not going to give me milk, she's not going to give me my favourite toy unless... I use my words.' That was a very challenging issue I faced. And it's 
still challenging sometimes... Where sometimes they don't want to speak or if they're in a bad mood... 'Ma, you should know what I want'... If they're not telling me what they want, they're not getting it... For a normal child this is our cultural thing that we do, that... we have to change the diapers before the [child asks for it] - when we know the diaper is wet... And the milk should come right before the child builds up time for milk... We just learned about this whole spectrum thing, that, okay, we have to wait until the child demands for it... but... being a mother, it's hard to see all of that crying and like you are not giving milk to your own child... Being a mother - it's painful to see. But, we know that it's the only thing that we can do to conquer that spectrum stuff. So that's why we did that.

In this excerpt, Anita portrays a home that has been reorganized to operate as a behavioural therapy clinic, where her parental conduct complies with the goals of ABA work, and where she ensures that other family members also comply. Anita's rationale for not doing the "normal cultural things" like giving her children milk and toys, or changing their diapers, is for them to perform the exercises required to "conquer" the "spectrum thing." Like Maya, Anita separates her ethical framework from mainstream culture's, by adopting a behavioural paradigm of personhood and care. Anita does not like taking on an authoritative role, which she experiences as painful, hard, and damaging to her identity as a mother. In stating that she just "learned about the whole spectrum thing" and was told that it is the "best thing she can do" for her children, Anita indicates how she has been trained by clinical experts to align being a good mother with being a good ABA practitioner. The jobs of good mother and good practitioner converge into the obligation to actively help conquer autism through completing ABA work. Although Anita and her family speak English as a second language, they speak only English around the autistic boys, on the advice of a behavioural therapy expert. Anita only learned about the spectrum through her children's diagnosis, so this ethnocentric orientation toward understanding and intervening on autism was taught to her by experts, and was formative in shaping her perception about how to care for her autistic children. Anita found it ethically necessary to responsibilize herself and her family to apply these "effective" yet painful interventions, because she is a good mother, because she does love her children.

\section{Conclusion}

Although applied behavioural therapies are sometimes practised outside of a psychocentric framework, as a field of discourse and practice, behavioural therapy reproduces psychocentrism, because it draws all actors involved into understanding autism through an individual deficit model. To be optimized, the autistic subject is subjected to normalizing disciplinary techniques and practices. Parents and providers are trained to view and accept clinical 
interventions as necessarily intense, and to consider the meaning of the lives of autistic people according to ideals of behavioural functionality, neurological capacity, and socialization. Self-discipline is the prime subjectification technique used in $\mathrm{ABA}$, where each subject involved must self-govern in order to govern others. My fieldwork indicates that the lifeworld of behavioural therapist informants was constituted through intensive training exercises, consisting of panoptic forms of audible, textual and video surveillance, and intra-therapeutic replicability. Exercises of compliance and reliability, aimed at creating the docile therapist, work to objectify her body and soul (i.e., use them as technical objects), so that she identifies her professional and personal worth through the ability to incite specific responses in her therapeutic subjects. The goal of effectiveness regulates expressions of care, training behavioural therapists and parapractitioners to define care for autistic people through a psychocentric framework. From a behavioural worldview, the good therapist is docile, and being a good person means being a good therapist. Another implication of behavioural therapy work is the complex gendered expectations that impact the work many therapists do. As particularly evident with Margot, Maya, and Anita, masculine ideals of objectivity, the self-disciplined body as technology, and the use of intensive methods, were considered essential to being empathetic toward autistic people.

$\mathrm{ABA}$ and EIBI professionals have not been the topic of much critical social scientific analysis, which problematically narrows discourse to a discussion of the ethics and effectiveness of applied behavioural therapies for autistic people. The research described in this paper thus draws upon the rich, culturally significant professional lifeworld encompassed in training for and practising behavioural therapy. Examining this lifeworld helps to understand the distinct epistemic culture that comprises this relatively new and increasingly popular expert field, which affects the everyday lives of most autistic people in Ontario and internationally. In addition, moving the discussion from the disciplining of the autistic person to the disciplining of the therapist allows an important analysis of expert knowledge and power: it is not just autistic people who are disciplined and monitored through governmental and pastoral forces (Foucault, 2008), which compel conduct toward collective norms. The complex network of power draws upon numerous subjects and technologies, such as clinical supervisors, training curricula, government policy, textual protocol, and video documentation. These technologies merge to shepherd the conduct of the behavioural therapist for the purpose of shaping the conduct of both autistic people and the experts themselves.

Intensive disciplining is both conceptual and material; autism is considered a problem of behavioural dysfunction, and care is understood as increasing functionality. However, through their entanglement and co-production with autistic people, behavioural therapists can reproduce or resist psychocentric aspects of their training. Whether therapists leave the field (as with Laurie or 
Leon), or choose a practice based on accommodation and social agency (as expressed by some of the other therapists I interviewed), closeness may provide openings for providing an ABA practice that is grounded in a social justice approach to autism care, where relationality, time-off, empowered support, inclusion, and enjoyment (for both therapists and autistic people) override psychocentric projects centred on repetition, replicability, intensiveness, dys/function, and assimilation. Social justice requires wider awareness and systemic recognition of the problem of psychocentrism when implementing social policies that aim to serve the interests of those involved.

\section{Acknowledgements}

Thank you greatly to the informants for this study, the editors of this issue and the anonymous reviewers for their valuable feedback. Thank you to Thea Lim, Emery Potter, Colin Hastings, Matthu Strang, and Eric Mykhalovskiy, for providing helpful comments on earlier versions of this paper.

\section{References}

Abu-Lughod, L. (1991). Writing against culture. In R. G. Fox (Ed.), Recapturing anthropology: Working in the present (pp. 137-148). Santa Fe, NM: School of American Research Press.

AnxiousAdvocate. (2015, May 22). Why I left ABA. Retrieved from https://sociallyanxiousadvocate.wordpress.com/2015/05/22/why-i-left-aba/

Autism Society of Canada. (2012, November 20). The right to treatment: the role of government. Retrieved from

http://www.autismsocietycanada.ca/index.php?option=com_content\&view=article\&id=30 \&Itemid $=63$

Autism Speaks/Cure Autism Now (2006, November 29). Cure Autism Now and Autism Speaks announce plans to combine operations. Retrieved from https://www.autismspeaks.org/about-us/press-releases/cure-autism-now-and-autismspeaks-announce-plans-combine-operations

Autistic Self Advocacy Network. (2015, December 7). Statement on Autism Speaks board appointments. Retrieved from http://autisticadvocacy.org/2015/12/statement-on-autismspeaks-board-appointments/

Auton vs. British Columbia, File 29508 (2002-2003). (The Supreme Court of Canada (On appeal from the British Columbia Court of Appeal) between the Attorney General of British Columbia and the Medical Services Commission of British Columbia, Applicants (Appellants/Respondents on Cross-Appeal) and Connor Auton et al., Respondents (Respondents/Apellants on Cross-Appeal): applications for leave to appeal and crossappeal, responses, and replies.)

Bagatell, N. (2010). From cure to community: Transforming notions of autism. Ethos 38(1), 3355.

Baggs, A. (2007, January 14). In my language. Retrieved from http://youtu.be/JnylM1hI2jc

Behaviourprise Consulting Inc. (2015, February 28). Toronto, Ontario. Retrieved from http://www.behaviorprise.com/

Broderick, A., \& Ne'eman, A. (2008). Autism as metaphor: Narrative and counter-narrative. International Journal of Inclusive Education, 12(5-6), 459-476. 
Clifford, J. (1986). Introduction: Partial truths. In J. Clifford \& G. Marcus (Eds.), Writing culture: The poetics and politics of ethnography (pp. 1-26). Berkeley \& Los Angeles: California University Press.

C.R. vs. Alberta. (1996). Action No. 9601-05499. (C.R. and H.R., appellants, and Child Welfare Appeal Panel and Director of Child Welfare, respondents, and The Attorney General of Alberta, intervenor.)

Davidson, J., \& Orsini, M. (2013). Critical autism studies: Notes on an emerging field. In J. Davidson \& M. Orsini (Eds.), Worlds of autism: Across the spectrum of neurological difference (pp. 1-30). Minneapolis, MN: Minneapolis University Press.

Dawson, M. (2004, January 18). The misbehavior of behaviourists: Ethical challenges to the autism-ABA industry. No autistics allowed: Explorations in discrimination against autistics. Retrieved from http://www.sentex.net/ nexus23/naa 02.html

Dawson, M. (2005, March 30). An autistic victory: The true meaning of the Auton Decision. No autistics allowed: Explorations in discrimination against autistics. Retrieved from http://www.sentex.net/ nexus23/naa_vic.html

Dawson, M. (2008, November 7). Gender disturbed children desperately need treatment. The autism crisis: Science and ethics in the era of autism politics. Retrieved from $\mathrm{http}: / /$ autismcrisis.blogspot.ca/2008/11/aba-success-stories.html

Defeat Autism Now. (2007, November 1). Retrieved from http://www.defeatautismnow.net/

Donzelot, J. (1979/1997). The policing of families. Baltimore, MD: John Hopkins University Press.

Eyal, G., Hart, B., Onculer, E., Oren, N., \& Rossi, N. (2010). The autism matrix. Cambridge: Polity Press.

Fabian, J. (1990). Presence and representation: The Other in anthropological writing. Critical Inquiry 16(4), 753-772.

F.E.A.T. (Families for early autism treatment). (1996-2016). Retrieved July 302016 from http://www.feat.org/

Foucault, M. (1977/1995). Discipline and punish: The Birth of the prison (A. Sheridan, Trans.). Paris: Editions Gallimard.

Foucault, M. (1991). Governmentality. In G. Burchell, C. Gordon, \& P. Miller (Eds.), The Foucault effect: Studies in governmentality (pp. 87-104). Chicago, IL: University of Chicago Press.

Foucault, M. (2008). The birth of biopolitics: Lectures at the College de France, 1978-1979 (G. Burchell, Trans.; M. Senellart, Ed.). Basingstoke \& New York: Palgrave Macmillan.

Goffman, E. (1961). Asylums. New York: Anchor Books.

Good, B. (1994). Medicine, rationality and experience: An anthropological perspective. New York: Cambridge University Press.

Gordon, A. (Nov 23 2012). The Autism Project: Children face up to a four year wait for therapy. The Toronto Star. Retrieved from https://www.thestar.com/news/gta/2012/11/23/the_autism_project_children_face_up_to_f ouryear wait for therapy.html

Hammer, K. (2008, August 28). Ontario parents battle for accessible autism therapies. The Globe and Mail, p. A9.

Jager, E. (2010, November 3). Autism self advocates: Please speak for yourselves. Autism Parents. Retrieved from http://autismparents.wordpress.com/2010/11/03/autism-selfadvocates-please-speak-for-yourselves/

Jasanoff, S. (2006). States of knowledge: The co-production of science and social order. London: Routledge.

Knorr-Cetina, K. (1999). Epistemic culture: How the sciences make knowledge. Boston, MA Harvard University Press.

Latour, B. (1988). Science in action: How to follow scientists and engineers through society. Cambridge, MA: Harvard University Press.

Lovaas, I. O. (1987) Behavioural treatment and normal educational and intellectual functioning in young autistic children. Journal of consulting and clinical psychology 55(1), 3-9.

Marcus, G.E. (1995). Ethnography in/of the world system: The emergence of multisited ethnography. Annual Review of Anthropology, 24, 95-115.

Studies in Social Justice, Volume 10, Issue 1, 38-58, 2016 
Ne'eman, A. (2011, September 21). The self-advocates/parent dialogue, day three: Ari Ne'eman. Thinking person's guide to autism. Retrieved from http://www.thinkingautismguide.com/2011/09/self-advocateparent-dialogues-daythree.html

Novas, C., \& Rose, N. (2000). Genetic risk and the birth of the somatic individual. Economy \& Society, 29(4), 485-513.

Ontario Ministry of Children and Youth Services. (2016, May 6). Intensive behavioural intervention. Toronto, Ontario. Retrieved from http://www.children.gov.on.ca/htdocs/English/topics/specialneeds/autism/ibi.aspx

Ontario Ministry of Education. (2007). Incorporating methods for applied behaviour analysis for students with autism spectrum disorders (ASD). Policy/Program Memorandum No. 140. Toronto, Ontario.

Orsini, M. (2009). Contesting the autistic subject: Biological citizenship and the autism/autistic movement. In S. Murray \& D. Holmes (Eds), Critical interventions in the ethics of health care (pp.115-130). London: Ashgate.

Orsini, M. (2012). Autism, neurodiversity and the welfare state: The challenges of accommodating neurological difference. Canadian Journal of Political Science, 45(4), 805827.

Orsini, M., \& Smith, M. (2010). Social movements, knowledge and public policy: The case of autism in Canada and the U.S. Critical Policy Studies, 4(1), 38-57.

Perry, A. (2002). Intensive early intervention program for children with autism: Background and design of the Ontario preschool autism initiative. Journal on Developmental Disabilities, $9(2), 121-128$

Rimke, H. (2010a). Consuming fears: Neoliberal in/securities, cannibalization, and psychopolitics. In J. Shantz (Ed.), Racism and borders: Representation, repression, resistance (pp. 95-113). New York: Algora Publishing.

Rimke, H. (2010b). Remembering the sociological imagination: Transdisciplinarity, the genealogical method, and epistemological politics." International Journal of Interdisciplinary Social Sciences, 5(1), 239-254.

Robinson, J.E. (2013, November 13). I resign my roles at Autism Speaks. Retrieved from http://jerobison.blogspot.ca/2013/11/i-resign-my-roles-at-autism-speaks.html

Rose, N. (1998). Inventing our selves: Psychology, power and personhood. Cambridge: Cambridge University Press.

Runswick-Cole, K. (2014). 'Us' and 'them': The limits and possibilities of a 'politics of neurodiversity' in neoliberal times. Disability \& Society, 29(7), 1117-1129.

Rutherford, R. 2009. Beyond the box: B.F. Skinner's technology of behaviour from laboratory to life, 1950s-1970s. Toronto: University of Toronto Press.

Schaber, A. (2014, February 27). Ask an autistic: What is ABA? Retrieved from https://youtu.be/PEhlSPB9w7Y

Sequenzia, A. (2016, Feb 8). Have some ABA, or else... Autism women's network: blog. Retrieved from http://autismwomensnetwork.org/have-some-aba-or-else/

Sequenzia, A. (2014, August 19). Is Autism Speaks a hate group? Autism women's network: blog. Retrieved from http://autismwomensnetwork.org/is-autism-speaks-a-hate-group/

Shyman, E. (2014). Besieged by behaviour analysis for autism spectrum disorder: A treatise for comprehensive educational approaches. Lanham, MD: Lexington Books.

Silverman, C. (2012). Understanding autism: Parents, doctors and the history of a disorder. Princeton, NJ: Princeton University Press.

Sinclair, J. (2002, June 26). Don't mourn for us. Autism network international. Retrieved from http://www.autreat.com/dont_mourn.html

Skinner, B. F. (1938). The behavior of organisms: An experimental analysis. Cambridge, MA: BF Skinner Foundation.

Skinner, B. F. (1971). Beyond freedom and dignity. Indianapolis, IN: Hackett Publishing.

Solish, A., \& Perry, A. (2008). The role of parent involvement in child outcome in IBI. Research in Autism Spectrum Disorders, 2, 728-738.

Solomon, A. (2008, May 25). The autism rights movement. New York Magazine: Features,News. Retrieved from nymag.com/news/features/4722 
Smith, T. (2001). Discrete trial training in the treatment of autism. Focus on Autism and Other Developmental Disabilities, 16(2), 86-92.

The Lovaas Center. (2016). Retrieved February 11, 2016, from http://thelovaascenter.com/aboutus/dr-ivar-lovaas/

Thierry, L. (Director). (2006). Autism every day. United States: Milestone Video, The October Group, Sundance Channel.

Traweek, S. (1992). Beamtimes and lifetimes: The world of high energy physicists. Boston, MA: Harvard University Press.

Turner, R. E., \& Edgley, C. (1983/2005). From witchcraft to drugcraft: Biochemistry as mythology. In H. N. Pontell (Ed), Social deviance: Readings in theory and research $\left(5^{\text {th }}\right.$ Ed.) (pp. 473-482). Upper Saddle River, NJ: Prentice Hall.

Unstrange mind: Remapping my world. (2014). ABA. Retrieved October 7, 2014, from https://unstrangemind.wordpress.com/2014/10/07/aba/https://unstrangemind.wordpress.co $\mathrm{m} / 2014 / 10 / 07 / \mathrm{aba} /$

Vermey, C. (2004, September 4). Letter to the editor: Autism is not a disorder that must be "cured." The Toronto Star. Retrieved from http://neurodiversity.com/vermey_letter.html

Wright, S. (2013, November 11). Autism Speaks to Washington: A call for action. Retrieved from https://www.autismspeaks.org/news/news-item/autism-speaks-washington-call-action

Zucker, C., \& Donovan J. (2016). In a different key: The story of autism. New York: Penguin/Random House. 